\title{
¿Existe América Latina? Reflexiones para una Historia de la educación
}

\author{
Does Latin America exist? \\ Reflections for a History of Education
}

Lidia Mercedes Rodríguez*

\section{RESUMEN}

Este artículo parte de la preocupación por el problema analítico y metodológico del abordaje de América Latina como unidad, en particular para la construcción de una historia de la educación. El interés por este tema surge debido a que, a pesar de muchos avances, la mayoría de los trabajos enfocan el continente como una sumatoria de países. En la primera parte se ubican autores que han sido centrales para pensar esta pregunta por la unidad, ligada fuertemente a la de la identidad. Indaga luego acerca de la construcción histórica de los diversos nombres con que esta geografía ha sido nombrada, desde el momento de llegada del invasor. En particular ubica el surgimiento del nombre de América Latina estrechamente ligado a la construcción de antagonismo con los intentos de expansión imperialista de diverso signo, y la marca identitaria que ello produjo. A partir de esta perspectiva señala avances realizados y líneas orientadoras en la delimitación de un campo analítico, y aportes para la construcción de ejes problemáticos y de una periodización en el campo de la historia de la educación.

Palabras clave: América Latina, historia de la educación, colonialismo

\section{ABSTRACT}

This paper refers to the analytical and methodological issue of studying Latin America as a unit. The interest in this topic rises from the fact that, in spite of the many progresses in this field, most academic works focus on the continent as a sum of countries. The first section identifies authors who have been central in thinking this question about unity, strongly linked to that of identity. Then, the paper reflects on the historical construction of the names given to this region since the invader's arrival. It detects, particularly, the origin of the name Latin America, closely linked to the construction of antagonism by the attempts of imperialist expansion of various kinds, and the identity mark that it produced. From this perspective, it points out the improvements and guidelines for marking out an analytical field, as well as the contributions to set up the problem areas and a periodization in the field of the history of education.

Key words: Latin America, history of education, colonialism

*Facultad de Filosofía y Letras. Universidad de Buenos Aires; lidiamero@gmail.com 


\section{INTRODUCCIÓN}

\section{Necesidad de repensar la historia de la educación}

El modelo educativo neoliberal que se ha profundizado y consolidado en la segunda década del nuevo milenio plantea un giro estructural respecto al modo en que, durante por lo menos los dos últimos siglos, se ha pensado la educación en el continente. La mirada histórica ayuda a pensar el presente desde nuevas perspectivas, tomar distancia de lo dado, complejizar la mirada, desnaturalizar los conceptos y asumirlos con sus tensiones internas. Facilita ubicar la situación presente en perspectiva, visualizarla como la sedimentación de procesos de larga duración y tomar por lo mismo conciencia de su temporalidad. Esa tarea contribuye a agudizar la mirada y a encontrar alternativas, pero sobre todo es imprescindible para que las lógicas teórico políticas de la construcción categorial y la interpretación no queden atrapadas de modo invisibilizado en el discurso hegemónico. En ese sentido es que la desnaturalización es un "proceso necesario, anterior al abordaje investigativo” (Gonçalves y Sooma, 2014, p. 124).

\section{El espacio disciplinar de la historia de la educación}

El espacio disciplinar de la historia de la educación ha crecido desde la recuperación democrática en el continente, la "vitalidad" y la "proliferación temática" parecen ser características importantes (Arata y Southwell, 2014). Sin embargo, la perspectiva latinoamericana no parece haber sido del interés predominante: “... la tarea es incipiente: los estudios comparados constituyen un aporte a esa mirada regional al poner en relación las particularidades nacionales (entre otros, Vidal y Ascolani, 2011), pero la pregunta por las especificidades latinoamericanas sigue abierta" (Carli, 2014, p. 107). Coincidimos con Roldán Vera respecto a la búsqueda de una perspectiva específica, que no sea una sumatoria o una comparación de países (Roldán Vera, 2013).

Este artículo atiende una de las preguntas centrales, anterior a su focalización en la cuestión educativa. Actualizar esta pregunta por "la existencia de América Latina" es un recaudo epistemoló- 
gico que colabora en la toma de distancia del sentido común, es parte de los controles de los condicionantes teóricos, experienciales o ideológicos (Zemelman, 2011). Por ello, no se limita a la cuestión educativa, que es su preocupación, sino que busca también el aporte de otros campos disciplinares.

En la primera parte se presentan los principales autores que han indagado acerca de la pregunta por la posibilidad de pensar la unidad continental, desde otros campos disciplinares, ubicando luego los que lo han realizado con una preocupación específica por la educación.

A continuación, se ubica un recorrido por los modos en que el continente ha sido nombrado, como modo de acercarse a la historicidad de la pregunta por su identidad.

En la tercera parte del trabajo se plantean modos en que el significante puede ser herramienta categorial para la construcción de un campo problemático educativo, el cual permite ciertos puntos centrales ordenadores de una lectura regional y de una periodización.

\section{UNA PREGUNTA CON HISTORIA}

¿América Latina existe? ... se preguntaba el intelectual brasileño Darcy Ribeiro (1992-1997) hace casi 40 años. Desde el periodo colonial cada país o centro de poder de la región se vincula directamente con la metrópoli y con los países centrales, sin lograr establecer una unificación política continental, que tampoco vendría dada por una homogeneidad lingüística, cultural o étnica. Sin embargo, el autor encuentra un factor homogeneizador: la expansión colonial ibérica (Ribeiro, 1979). Es en algún sentido similar la pregunta que muchos años después formula el importante historiador argentino Halperín Donghi (1926-2014), y, desde otra posición ideológica, sostiene también que la situación colonial es el rasgo que permite hallar una unidad en la historia de América Latina contemporánea (Halperin Donghi, 2005). Ansaldi argumenta también, citando a Yepes: "Y es esta historia común de colonialismo y dependencia lo que realmente permite agrupar a tantos países y culturas diferentes bajo el rótulo de América Latina” (Ansaldi y Giordano, 2012, p. 63). 
A fines de la década de los cincuenta, el historiador mexicano O'Gorman (1905-1982) marcó un hito en el modo de pensar la historia en el continente (O'Gorman, 1958). Su tesis central fue que "América" no sólo no había sido "descubierta", en el sentido que ya era conocida por los habitantes originarios de estas tierras. Más radicalmente, sostuvo que fue "creada" en el proceso de su conquista y colonización. Esta tesis es compartida por el intelectual argentino radicado en Estados Unidos, Walter Mignolo (2005, p. 31), una de las figuras centrales del pensamiento poscolonial: “O’Gorman sacó a la luz una dimensión de la historia ocluida por los relatos parciales del 'descubrimiento', lo que sirve de ejemplo para comprender cómo se ven las circunstancias desde las diversas experiencias de la colonialidad".

América Latina no remite a un referente empírico que estuviera ya ubicado ahí; ha sido históricamente construida, y puede sostenerse que encuentra en la situación colonial el elemento común que permite construir la unidad del objeto. Como un modo de aproximación a la historicidad de esa identidad, recorremos más abajo -un poco sucintamente- los nombres que esta zona geográfica ha ido adquiriendo a lo largo de su historia.

\section{La pregunta en el campo de la historia de la educación}

Ubicados en el campo educativo, Southwell y Arata formulan también la pregunta a los investigadores de cada país que reúnen en su compendio: ¿Puede escribirse una historia de la educación latinoamericana que trascienda la compilación de experiencias nacionales? (Arata y Southwell, 2014, p. 202). En el texto clásico de historia de la educación, Weinberg (1986, p. 432) coincide en la dificultad para la unidad dada por la heterogeneidad: "la complejidad de la estructura del continente, con más de veinte países de extensión y recursos muy desiguales y niveles de desarrollo harto distintos, dificultan la tarea de ofrecer una imagen de conjunto". El autor plantea también la otra pregunta, que surge siempre, vinculada a la idea de la unidad, referida a aquello que nos haría singulares.

Puiggrós y Lozano, el otro texto clásico del campo educativo, eligen partir de una posición respecto a la unidad del objeto, y no 
de una duda. Entonces la heterogeneidad ya no es una dificultad, sino una característica, probablemente la más importante. Así, "el tema central de la pedagogía iberoamericana es precisamente la vinculación conflictiva entre lógicas espacio-temporales, políticas culturales distintas. Se trata más bien de dar cuenta de tales conflictos" (Puiggrós y Lozano, 1995, p. 15). También desde el campo de la educación, el investigador uruguayo Bralich (1934) seńala sus reparos respecto a la posibilidad de construir la unidad del objeto, pero sostiene, en cierta consonancia con varios de los autores citados: "Aun así, el peso de la tradición cultural originada en la conquista y posterior colonización ha generado ciertos rasgos similares en los sistemas educativos de los países latinoamericanos" (Bralich, 2014, p. 97).

\section{BÚSQUEDA DE UN NOMBRE, BÚSQUEDA DE IDENTIDAD}

\section{Pueblos originarios}

Fueron ricas, complejas y diversas las formas de trasmisión cultural del mundo indígena, aunque en este trabajo no nos detendremos en ese punto. Pero sí interesa remarcar que, a pesar de que, como muchos autores sostienen, a la llegada del europeo no existía un nombre que designara la totalidad del continente (Piñeiro, 2006; Gallego, Eggers-Brass y Gil, 2006), el concepto Inca de "Tahuantinsuyo" - "las cuatro regiones unidas entre sî"- pone en evidencia que la idea de unidad no era ajena a los primeros pobladores Esa aspiración fue tempranamente imposibilitada por la invasión europea y la devastación que produjo (Rostworowski, 2008, pp. 19-20).

\section{Siglos XVI a XVIII}

En los primeros años de la llegada de los europeos, se utilizaban diversidad de nombres, como "Terra Nova", "Terra Santa Crucis", "Perú", "Cuba”, "Florida”. Fray Bartolomé de las Casas proponía "Terra de Gracia” e "Ínsula Atlántica" (Funes, 2007). La primera denominación cartográfica fue la de "Mundus Novus" dada por Américo Vespucio en 1503. Ese nombre, como otros, 
fue una marca fundacional de esa mirada extrañada, y también seducida del invasor, que forma parte central del proceso de constitución de esta compleja identidad continental que la literatura llamó "Soledad” (García Márquez, 1982).

El nombre de América aparece por primera vez en un mapa fechado en 1507, elaborado en la abadía de Saint Dié, donde los monjes -el geógrafo Martín Waldseemüller- rindieron homenaje al cartógrafo, para muchos en detrimento del muchísimo más merecido reconocimiento que merecía el viajero italiano (Funes, 2007). El nombre será luego retomado por el cartógrafo flamenco Gerardus Mercator en su mapa del mundo editado en 1538. Se iniciaba una "tradición cartográfica" eurocéntrica que borró las perspectivas de los pueblos originarios (Gonçalves y Sooma, 2014).

\section{Siglo XIX}

14 La fragmentación de la unidad de las colonias en múltiples naciones en el proceso independentista actualizó el problema de la unidad y el de la identidad. Quizá uno de los primeros rastros de esta preocupación en el discurso pedagógico se encuentra en el difundido texto del "Catecismo Político Cristiano dispuesto para la instrucción de los pueblos de América Meridional", de autor anónimo, que circulara en Chile en el ambiente independentista de 1810: "La división, la falta de acuerdo y de unión es mil veces peor que la pérdida de la mitad de nuestros derechos; con ella los perderíais todos" (Amor de la Patria, n.d., p. 6).

"Mi Patria es América" decía San Martín. Lo mismo hace Bolívar, aunque a veces le agrega "del Sur", o "antes española”. A pesar de su origen europeo, "América" fue la denominación utilizada por los independentistas latinoamericanos. La crítica decolonial cuestiona esos procesos por la lejanía de las problemáticas indígenas, negras, campesinas, que constituían la mayoría de los pueblos del continente, y rechaza entonces el nombre de América (Mignolo, 2005). La necesidad de un nombre común renació frente a las acciones expansionistas norteamericanas: la anexión de Texas en 1845, la Guerra mexicana (1846- 1848), la fiebre del oro en California, los intereses en una ruta interoceánica a través 
del istmo de Panamá, la constante presión por anexar Cuba, la invasión de Nicaragua por William Walker en 1855. Comienza a usarse entonces con más frecuencia el término de Hispanoamérica, parecería que allí se encuentra un elemento de unidad cultural, y en particular en la lengua (Ardao, 1978).

Francisco de Miranda (1750-1816) proponía, desde fines del siglo XVIII, el uso del nombre de Colombia, en inequívoca evocación a Colón, a quien menciona en varias oportunidades con su nombre italiano Colombo. También lo usará Bolívar (1783-1830) y el pedagogo que es conocido como su maestro, con quien tuvo una entrañable relación de afecto, Simón Rodríguez (1868-1854). Miranda también inaugura "Nuestra América", que será retomada por Martí (1853-1895) a fines del siglo XIX, en el contexto de la emancipación de la isla cubana del dominio español.

Respecto al origen del nombre de América Latina podemos ubicar dos tesis. Por un lado, la muy difundida del historiador de la Universidad de Wisconsin, John L. Phelan (1924-1976), que sostiene que esa denominación fue creación francesa para justificar sus proyectos expansionistas sobre el continente (Phelan, 1979). Por otro lado, otros autores presentan datos para argumentar que el nombre tiene su origen en intelectuales latinoamericanos. Para el uruguayo Ardao (1912-2003), el primero en usar el nombre fue Torres Caicedo (1830-1889), colombiano residente en Francia, y defensor de la Unidad Sudamericana. Para otros (Rojas Mix, 1986; Fabelo Corzo, 2014; Arpini, 2013; García San Martín, 2013), el primero en utilizar el nombre es el chileno Bilbao (1823-1865). En ambos casos se trata de una afirmación identitaria frente al expansionismo norteamericano de mediados del siglo XIX. Lo que interesa de esos planteos, desarrollados más detalladamente en otros trabajos (Rodriguez, 2018), es que ponen en evidencia una tensión central en la constitución de la identidad latinoamericana: es referente de un discurso construido por el conquistador, objeto de sueños de dominación; o es un enunciado que produce el sujeto de proyectos emancipatorios.

Desde la perspectiva de la colonialidad se rechaza el nombre de América Latina, especialmente por el borramiento que la "latinidad" hace de las múltiples etnicidades de esta región (Mignolo, 2005, p. 358). Caicedo, Bilbao y muchos otros intelectuales del 
siglo XIX, muchos de ellos vinculados al campo educativo, estarían probablemente de acuerdo con Mignolo. Esta objeción, que repone la centralidad de la problemática de la situación colonial en la constitución histórica y en la geopolítica del continente, plantea una tensión que forma parte de la matriz constitutiva de la identidad latinoamericana. Conviene no olvidar esta perspectiva crítica, que vincula el nombre de América Latina en el marco de una "estrategia de control y demarcación" (Gonçalves y Sooma, 2014, p. 123). Pero el significado de las palabras no es isomórfico a una empiria que les preexiste, sino el resultado, siempre provisorio, de procesos históricos de larga y mediana duración.

Biagini enfatiza, a diferencia de lo ocurrido por ejemplo con la Comunidad Europea, su capacidad para generar pensamiento: "la idea latente de una gran nación americana exhibe una tradición teórica y activa que, desde los tiempos de la Independencia, ha sido sostenida por diversos expositores y corrientes cuya divulgación ha dado lugar a un vastísimo corpus literario y político junto a una exégesis no menos frondosa" (Biagini, 2000, p. 2).

\section{Siglo XX}

Las primeras décadas del siglo hacen un punto de inflexión para la historia continental, marcada por la Primera Guerra Mundial (1914-1918), la Revolución Rusa (1917), y la Revolución Mexicana (1910), además de las transformaciones sociales tales como el crecimiento de las capas medias. Se inicia un periodo de crisis de la dominación oligárquica y resurge la idea de una América Latina antiimperialista (Ansaldi y Giordano, 2012).

Para el pensamiento latinoamericano, el siglo se inicia con el "Ariel” del uruguayo Enrique Rodó (1871-1917). En fin, las primeras décadas del siglo están marcadas por una nueva búsqueda identitaria (Devés, 2000). Algunas perspectivas enfatizan el antagonismo político, en una posición claramente antiimperialista; otras enfatizan la multiculturalidad y etnicidad del continente. En todo caso se reafirma la preocupación social, y crece un pensamiento antiimperialista, indigenista, socialista y nacionalista. Vasconcelos (1882-1959), Secretario de Educación Pública en 
México durante la presidencia de Álvaro Obregón, hablará de "La Raza Cósmica" (1925), concebida como una suerte de síntesis que recupera la tradición hispánica, articulada a elementos indígenas, campesinos, populares; oponiendo lo latino-hispano-indígena a lo sajón. Ricardo Rojas (1882-1957) construye "Eurindias" (1925). La idea de la tradición española será retomada también por un pensamiento progresista. El dominicano Pedro Henríquez Ureña (1884-1946) utilizaba el de América Hispánica. También el argentino Manuel Ugarte (1878-1951) reivindica lo hispánico de la formación argentina, marcando con claridad una posición antiimperialista, y proponiendo una educación latinoamericana.

Para el peruano Haya de la Torre (1895-1979), que funda el Partido de Alianza Popular Revolucionaria Antimperialista (APRA) en 1924, y que tomara el gobierno en el Perú en los años 80, Hispanoamérica correspondería a la época colonial, y acepta el uso de Latinoamérica a la etapa republicana, más allá del uso que Francia haya querido darle. Pero para el momento de su presente, proponía "Indoamérica",

Indoamericanismo es la expresión de la nueva concepción revolucionaria de América, que, pasado el periodo de las conquistas ibéricas y sajonas, se estructurará en una definida organización económico-política y social, sobre la base nacional de sus fuerzas de trabajo representadas por la tradición, la raza y la explotación de sus indígenas, que en el total de la economía americana -cuya unidad es indestructible- representan desde la época precolombina la base de nuestra productividad y la médula de nuestra vida colectiva (Haya, 1995, pp. 20-21).

El mismo autor (Haya, 1931) planteó la diversidad de ascendencias de la población americana, y propuso también "iberolusitano-franco-África-América" (UNLa, 2017, p. 639). También se ha propuesto "Afroamérica", en reconocimiento de la importante influencia africana en la constitución de los pueblos latinoamericanos.

No puede estar ausente de este breve recorrido el peruano José Carlos Mariátegui (1894-1930), el primero que buscó apropiarse de un modo original, desde la realidad local, del aparato conceptual del marxismo (Quijano, 2007). A pesar de que debate 
fuertemente con Haya, y aunque utiliza diversos nombres para el continente (Hispanoamérica, Ibero América, Latino América, América española, Nuestra América, América indo española, América indo-ibera), prefiere también incorporar la idea indígena como rasgo identitario (Rojas, 1997). En sus propias palabras: "No queremos, ciertamente, que el socialismo sea en América ni calco ni copia. Debe ser creación heroica. Tenemos que dar vida, con nuestra propia realidad, en nuestro propio lenguaje, al socialismo indoamericano" (Mariátegui, 1928, s/d). Mariátegui es un pensador central para la cuestión pedagógica, y en ese sentido es importante señalar al menos un rasgo central: su crítica al "educacionismo", en el sentido de la reducción de la problemática del indio a una cuestión pedagógica, cultural o moral; obliterando la dimensión económica.

La cuestión indígena arranca de nuestra economía. Tiene sus raíces en el régimen de propiedad de la tierra. Cualquier intento de resolverla con medidas de administración o policía, con métodos de enseñanza o con obras de vialidad, constituye un trabajo superficial o adjetivo, mientras subsista la feudalidad de los "gamonales" (Mariátegui, 1928, p. 26).

Después de la Segunda Guerra Mundial, el nombre de América Latina se impuso para las instituciones internacionales que ahí surgieron. La Comisión Económica para América Latina (CEPAL) de las Naciones Unidas (1948) fue el primer organismo internacional con ese nombre. En 1957 se creó la Facultad Latinoamericana de Ciencias Sociales (FLACSO), y en 1967 el Consejo Latinoamericano de Ciencias Sociales (CLACSO). América Latina fue también el nombre retomado con su carga emancipatoria por los movimientos revolucionarios de las décadas de los sesenta y los setenta (Ansaldi y Giordano, 2012).

\section{América Latina: su historicidad}

El significante "América Latina” si bien fue utilizado a comienzos del siglo XIX con aspiraciones imperialistas, resultó ser apropiado desde entonces por la juventud intelectual latinoamericana, que lo utilizó, en primer lugar, como núcleo de sentido de un discur- 
so de oposición a la dominación. Ese uso tuvo gran capacidad para lograr interpelaciones exitosas, fue potente en el sentido de organizar una superficie identitaria. Vale la pena, sin embargo, tener presente que la permanencia de la nominación que es heredada del colonizador pone en evidencia las tensiones constitutivas de esa identidad. Ellas, por otra parte, pueden ser leídas más que como debilidad, como originalidad y potencialidad. Plantear las tensiones cuestiona relatos biunívocos, pone en evidencia la complejidad contradictoria de la conformación de esta zona geopolítica, nos recuerda que, si la identidad es una articulación, será de elementos heterogéneos, siempre precaria, resultado de la práctica y libre de fundamentaciones esencialistas. Este breve recorrido por algunos de los principales nombres de este vasto territorio, nos permite dar cuenta de la construcción histórica de su unidad en tanto concepto, articulada sobre el eje del antagonismo, abriendo la posibilidad de utilizarla como categoría ordenadora de un campo problemático.

\section{EL CAMPO PROBLEMÁTICO DE LA EDUCACIÓN EN AMÉRICA LATINA}

La idea de campo problemático se sostiene en la perspectiva analítica según la cual se supone que el razonamiento "no se orienta a la reconstrucción de un objeto particular, sino más bien al trazado de un campo de objetos" (Zemelman, 1992b, p. 116). Así, la educación latinoamericana puede ser abordada como campo problemático heterogéneo, complejo, atravesado por diversidad de posicionamientos teóricos, políticos, ideológicos, de fronteras porosas y móviles, capaz de alojar un conjunto de preguntas. En el esfuerzo de su construcción, la categoría ordenadora permite avanzar en "una exigencia de totalizar lo fragmentario". Es imposible una "historia total", tal como plantean Arata y Southwell (Arata y Southwell, 2014), desde la perspectiva de un "un 'todo' real". En ese sentido, "la totalidad no es todos los hechos, sino que es una óptica epistemológica desde la que se delimitan campos de observación de la realidad” (Zemelman, 1992a, p. 50). Es decir, aquí entendemos la totalidad como un "enfoque epistemológico, esto es, como una forma de organización del razonamiento abier- 
ta a la complejidad de lo real y fundamentalmente, crítica, para evitar toda clase de reduccionismo" (Zemelman, 2011, p. 34). Como sostienen los historiadores de la educación:

proyectar luces sobre América y sobre América Latina significa (o debería significar) observar el conjunto de circunstancias que estuvieron (y, de algún modo, permanecen) presentes en las estrategias políticas, en las demarcaciones, en las disputas por la hegemonía de la región, en las proyecciones cartográficas (con sus indisociables distorsiones). Algo, pues, que se relaciona con el universo complejo y extremamente diverso en la historia y la cultura que constituyó (y constituye) la pluralidad de experiencias que configuran lo que, como hemos visto, convencionalmente se llama América y América Latina (Gonçalves y Sooma, 2014, p. 123).

Es decir, no sólo los modelos que lograron constituirse como hegemónicos, sino las luchas y las tensiones, a veces invisibilizadas y no siempre fáciles de recuperar, debido en gran parte al problema de las fuentes. Pero también, debido a la debilidad una construcción categorial que permita dar cuenta de las disputas, de las tramas profundas, de la recuperación de la memoria.

Para resolver el tema, Weinberg elige una categoría que, como suele ocurrir, se la proveen otros espacios disciplinares: modelos o estilos de desarrollo. Al ser un concepto de raíz latinoamericana, le permite objetivar una realidad específica, evitando la operación tan común del "trasplante" desde otras problemáticas. Un estilo de desarrollo es:

un proceso dialéctico entre relaciones de poder y conflictos entre grupos y clases sociales, que derivan de las formas dominantes de acumulación de capital, de la estructura y tendencias de la distribución del ingreso, de la coyuntura histórica y la dependencia externa, así como de los valores e ideologías (Weinberg, 1984, p. 10).

El uso de esa categoría de "modelo" le permite analizar las relaciones entre distintos planos, como el modelo educativo y el de desarrollo. Le permite analizar el proceso respetando la especificidad de lo educativo. Y también distinguir entre "ideas", que pudieron o no tener "éxito" en la "práctica”, de acuerdo con su 
pertinencia para la "realidad", y la existencia o no de "agentes" para su concreción.

Otro ejemplo de categorías interpretativas es la de la "Escuela expansiva" y "competitiva" que permiten a Martínez Boom (2004) organizar una mirada continental para la historia reciente. Necesitamos avanzar en la elección de categorías específicas, para poder delimitar corpus de análisis y decisiones metodológicas, desde esta perspectiva analítica. Son útiles, para el campo específico de la pedagogía, por ejemplo, algunas como "Imperialismo" (Puiggrós, 1980; Carnoy, 1993), "Educación Popular” (Puiggrós, 1998; 1988) y "Alternativas" (Puiggrós y Gómez, 1994). En el marco del proyecto APPEAL se han trabajado otras, especialmente para la sistematización de experiencias (Gómez y Corenstein, 2013). También "Saberes" (Puiggrós y Rodríguez, 2009) y "Saberes Socialmente Productivos" (Puiggrós y Gagliano, 2004), por citar algunos ejemplos.

Aunque no es el objetivo de este trabajo, vale la pena señalar al menos algunos posibles enfoques metodológicos y temáticos. Se requiere definir problemas para el abordaje, porque, de otro modo, "América Latina" se transforma en un "imposible epistemológico": "Quien pretenda hacer una historia global de la educación debe hacer explícitos los aspectos en los que centrará su mirada, aceptando que dejará por fuera muchos otros" (Álvarez y Taborda, 2014, p. 163). Con frecuencia se ha señalado la importancia de que se definan problemas "de valor social y pertinencia" (Toro, 2014, p. 87). Ya el clásico texto de Weinberg (1984) también se preocupa por la escasa importancia dada a temas centrales en el continente por parte de la historia de la educación. Un ejemplo interesante de tema pendiente de ser abordado por la historia de la educación es el tema migratorio, por su importancia actual y en la historia de la educación del continente (Carli, 2014, p. 107).

Por otra parte, vale la pena dejar al menos planteado que, desde la perspectiva de su construcción a nivel latinoamericano, los temas ofrecen también dificultades de distinto orden. Algunos remiten directamente a la perspectiva continental, cuando se trata de momentos, temas o hechos que trascendieron las fronteras nacionales, $\mathrm{y}$ fueron planteados en términos más amplios 
por los propios actores del proceso histórico. Por ejemplo, la Reforma Universitaria (Puiggrós, 1998), la Educación popular que se desarrolla en los años sesenta, o las Reformas para la historia reciente (Gómez y Corenstein, 2013; Rodríguez, 2013). Un grupo distinto es el de temas que se difundieron en América Latina, como el del Sistema Lancasteriano. Para abordarlo, Roldán Vera (2002) elige cuatro formas de narrativas, que toma de Crossley (Crossley, 2007): convergencia, contagio, divergencia y sistemas. Otra forma de resolución metodológica es la elección categorial como eje de investigaciones ubicadas regionalmente en diferentes lugares. Por ejemplo, el tema de "saberes escolares" (Álvarez y Taborda, 2014), "Infancia” (Herrera y Cárdenas, 2014), o "Universidad" (Tünnermann, 1991). El clásico trabajo de Prieto Figueroa (1980) sobre estado docente en América podría ubicarse también en ese grupo. Un camino interesante para esta necesaria desnaturalización de los conceptos, que queda planteado, es el de las representaciones que el mismo fue adquiriendo, en particular para los historiadores de la educación (Gonçalves y Sooma, 2014). En muchos de estos casos, el enfoque comparativo podría resultar muy adecuado, teniendo en cuenta que no se transforme en una serie de yuxtaposiciones (Toro, 2014, pp. 84-85).

De todos modos, este trabajo no se focaliza en la cuestión metodológica, sino que se centra en la pregunta por la posibilidad de la construcción de América Latina como categoría ordenadora. Ello, en buena medida, porque partimos del supuesto de que es la perspectiva analítica, y en particular el tipo de categorías seleccionadas para la organización del campo problemático la que ordena, en primera instancia, la mirada interpretativa, y la que ubica la dimensión política constitutiva del trabajo conceptual.

\section{¿EXISTE UNA "PEDAGOGÍA LATINOAMERICANA"?}

Desde la perspectiva que hemos planteado, la especificidad de una pedagogía latinoamericana no se encuentra en elementos o aspectos particulares, permanentes, que permitieran construir definiciones cerradas e inmutables. Como venimos planteado, más bien puede pensarse como construcción de un campo problemático organizado en torno a ciertas categorías, que se acer- 
quen al análisis desde cierto tipo de mirada. Es en ese sentido que ubicar la lógica identitaria del continente, que se organizó en oposición a la de la dominación, orienta la búsqueda hacia la idea emancipatoria como una perspectiva capaz de dar posibilidades de unidad al conjunto. Ese horizonte, que abre un campo de visibilidad particular, organiza una cierta periodización, y focaliza la mirada en una serie de problemas particulares en el campo de la pedagogía, tales como su relación con otros planos de lo social, el tipo de modelo político-académico, ${ }^{1}$ la constitución de su sujeto pedagógico, es decir, el sujeto constituido en el específico plano educativo (Puiggrós, 1990). Son muchos los nombres de una educación latinoamericanista que surgen desde esa mirada, Simón Rodríguez, Martí, Mariátegui, el argentino Ugarte; así como las experiencias educativas colectivas, como fue la escuela de Warisata en Bolivia, la Campańa educativa cubana, la experiencia de la DINEA en la Argentina, etc. Para este artículo elegimos cuatro temas o momentos, que permiten ubicar al menos ciertos ejes ordenadores y momentos para una periodización.

Puiggrós conceptualiza un momento inicial de la educación moderna en América Latina con la hipótesis de la "escena fundante" (Puiggrós, 1996). Ello ubica un punto de partida como un momento traumático, donde se organiza una matriz de imposición cultural bajo amenaza de aniquilación. Se trata de la decisión de la Corona española respecto a la necesidad de informar a los Indios de la nueva situación que la llegada del europeo implicaba. Para ello, antes de proceder a tomar posesión de las tierras se debía leer un texto redactado por uno de los más importantes juristas de la Corte, denominado "Notificación y requerimiento que se ha dado de hacer a los moradores de las islas en tierra firme del mar océano que aún no están sujetos a Nuestro Señor" (Palacios, 1513). El punto central de ese documento es el que advierte sobre la destrucción de los pueblos que no aceptaran al Dios Cristiano, es decir, justifica la aniquilación frente a la no aceptación de la "verdad" del invasor. La escena se continúa

\footnotetext{
1 "Se refiere a la característica dominante en el conjunto de reglas explícitas o implícitas que organizan las relaciones pedagógicas en su aspecto político y regulan las formas de participación, decisión, evaluación, promoción, gestión, etc." Manual para uso de usuarios del Sistema de Información del proyecto Alternativas Pedagógicas y Prospectiva Educativa para América Latina (SIAPPEAL). s/f. No publicado.
} 
con las diversas reacciones de los primitivos habitantes frente a tal avasallamiento, que fueron en general de sorpresa, defensa, y también desprecio frente a la brutalidad de los recién llegados. La escena es fundadora pues constituye matriz, organiza una gramática, y, sobre todo, porque podemos encontrar su repetición en diversos momentos de la historia de la educación continental.

Ese mismo sentido de imposición cultural profundamente violenta se continúa con la lógica civilizatoria, que fuera expuesta por Sarmiento en el texto emblemático de "Civilización y Barbarie. Vida de J. F. Quiroga”, cuya primera publicación es de 1845. Ese texto, que fue fundacional para pensar luego los sistemas escolares, se inicia convocando a la barbarie como un espectro amenazante que es necesario conjurar, cuya presencia supera la muerte biológica. Pero lo que interesa señalar en particular es la intuición, la certeza de que, en esa zona que requiere ser eliminada, existen secretos que no son accesibles desde la lógica de la dominación.

¡Sombra terrible de Facundo, voy a evocarte, para que, sacudiendo el ensangrentado polvo que cubre tus cenizas, te levantes a explicarnos la vida secreta y las convulsiones que desgarran las entrañas de un noble pueblo! Tú posees el secreto: ¡revélanoslo! Diez años aún después de tu trágica muerte, el hombre de las ciudades y el gaucho de los llanos argentinos, al tomar diversos senderos en el desierto decían: “№, no ha muerto! ¡Vive aún! ¡Él vendrá!” ¡Cierto! Facundo no ha muerto; está vivo en las tradiciones populares, en la política y las revoluciones argentinas, en Rosas, su heredero, su complemento (Sarmiento, 1953, p. 3).

La amenaza espectral se conjuró con la creación de un dispositivo escolar que, por otra parte, no puede ser comprendido en términos dicotómicos de pura dominación. Por el contrario, la escuela fue también profundamente democratizadora, especialmente en términos de legitimar y organizar un espacio de igualdad, disponible para todos, sustraído a la lógica de la ganancia y el trabajo (Rancière, 1988). Pero esa operación tuvo en América Latina el costo de creación de un nuevo horizonte cultural, que construyó un nuevo nombre de la exclusión y, sobre todo, ordenó una lógica del conocimiento articulada a la lógica de la dominación. 
El discurso escolar impuso una jerarquía cultural, ordenó un campo de visibilidad. Excluyó, deslegimitó, lo que consideró bárbaro, irracional. Pero esos mundos construyeron otros espacios para habitar, que han continuamente interpelado a la escuela. Como señalan, por ejemplo, muchos trabajos que analizan la relación de la escuela con los diversos medios de comunicación. Ford lo expresa con mucha claridad:

los Estados modernos jerarquizaron la escritura casi como única forma de comunicación y de información, desplazando otras formas, otros canales. De alguna manera nuestra cultura bloqueó la reflexión, el conocimiento sobre la percepción corporal, kinésica y proxémica, el rol de los sentidos en nuestra experiencia cotidiana. ... Culturas del afecto y del sentimiento, del azar y la incertidumbre, del misterio y de lo negro, de la actuación y la improvisación, del humor y la irrespetuosidad, de la aventura y la "pulsión exploradora", de lo oral y lo "no verbal", de la cotidianeidad y de la construcción cotidiana del sentido ... del juego, la fiesta, la simulación y el entretenimiento, fueron desjerarquizadas por las culturas oficiales aquellas que desde el Estado, o no, cumplían un rol organizador de la sociedad- ... que las consideraban bárbaras, irracionales (Ford, 1994, pp. 71-72).

En fin, a finales del siglo XIX la creación y expansión de los sistemas escolares, también herederos de aquella escena fundante, organizan lo que hoy ya es una "tradicional división de lo sensible que separa el mundo en hombres de saber y de cultura y en hombres de empiria y de rutina” (Rancière, 2008, p. 17).

Un hecho central en la constitución de un pensamiento pedagógico latinoamericano fue la Reforma Universitaria de 1918, iniciada en Córdoba y rápidamente expandida a todo el continente. El clima cultural de principios de siglo, con figuras que mencionamos antes como Haya de la Torre, Mariátegui, Ugarte, fueron centrales para pensar el tema educativo desde la realidad continental y en un sentido antiimperialista (Puiggrós, 1998; Portantiero, 1987).

Desde esta perspectiva la principal contribución de Paulo Freire fue la de ubicar un nuevo nombre para la barbarie, poniendo en evidencia el carácter político de ese enunciado, que 
pretendía sostenerse en un registro cultural. Influido, sin duda, por el trabajo de Fanon, conociendo zonas profundas de América Latina como el Norte de Brasil, señala el "Oprimido" como el destinatario de una pedagogía, visibilizando la especificidad del sujeto pedagógico de este continente (Rodríguez, 2015). Esa preocupación emancipatoria lo aleja de las tesis reproductivistas de su tiempo. Gran parte del valor de su trabajo es su carácter propositivo. En particular, porque establece principios metodológicos coherentes con el horizonte liberacionista, que logran no sólo denunciar los aspectos de dominación de la pedagogía hegemónica en su tiempo que llamó "bancaria", sino produjo una dislocación de los discursos pedagógicos heredados y en ese sentido marca un hito en la historia de la educación continental. Como señala Puiggrós, el planteo freireano corroe el discurso pedagógico moderno basado en "la relación bancaria, la creencia en la importancia de las posiciones de educador y educando, el recurso a la lógica de la similitud, identidad y homogeneidad para construir el discurso educativo; y el mito de la separación entre educación y política” (Puiggrós y Mc. Lharen, 1993, pp. 195-196).

\section{A MODO DE CIERRE}

Los diversos mestizajes étnicos entre europeos y pueblos originarios, a los que pronto se sumaron los africanos traídos como esclavos; la amalgama lingüística y cultural que eso produjo; los procesos históricos que fueron generando distinto tipo de fronteras políticas produjeron, desde 1492, preguntas respecto a la identidad de esta vasta Región.

Un breve recorrido por tensiones y cambios respecto al nombre de esta geografía dan cuenta de la existencia de "América" y "América Latina" en tanto conceptos socialmente construidos, abiertos por lo mismo a nuevas construcciones. Por otra parte, ese recorrido da cuenta también de esa constante pregunta por su unidad, ligada a la de su identidad, de ese horizonte utópico de unidad desde los tiempos del Tawantinsuyu. Un elemento común a su heterogeneidad política, geográfica, cultural, lingüística, étnica ha sido un tipo particular de relación con los centros de poder, que ha recibido distintos nombres y ha sido caracteri- 
zada también con matices diversos: colonialidad y neocolonialidad, dependencia, situación periférica, imperialismo, cultura "impuesta", opresión, o antagonismo con los intereses imperiales, han sido las denominaciones más usadas.

Esa situación ha tenido traducciones que la especifican para el campo de la pedagogía, que permiten ubicar algunos hitos para ordenar una periodización. En particular, entre otras construcciones categoriales, ubicamos la hipótesis de la "escena fundante", que encuentra una suerte de repetición en la lógica civilizatoria del siglo XIX, y es parte sustantiva de los fundamentos de construcción de los sistemas escolares. En el clima cultural de principios de siglo se reactualiza la cuestión identitaria, y en el plano educativo la Reforma Universitaria construye un discurso de mirada continental antiimperialista. Si bien son muchos de los nombres que desde el campo educativo produjeron propuestas en lógica emancipatoria, puede ubicarse un punto de inflexión a mediados del siglo XX con la propuesta freireana. En particular, con la ubicación en el registro pedagógico del problema de la colonialidad y la visibilización del oprimido como un sujeto particular del continente.

\section{REFERENCIAS BIBLIOGRÁFICAS}

Álvarez, A. y Taborda, M.A. (2014). La historia de los saberes escolares: nuevas miradas a la historia de la educación en América Latina. En M. Sowthwell, y N. Arata (Ed.), Ideas en la educación latinoamericana. Un balance historiográfico. (pp. 163-180). Gonnet: UNIPE.

Amor de la Patria, J. (1810). Catecismo Político Cristiano Dispuesto para la Instrucción de la Juventud de los Pueblos de la América Meridional. Chile: Memoria Chilena. Biblioteca Nacional de Chile. Recuperado de http://www. memoriachilena.cl/602/w3-article-92740.html

Ansaldi, W. y Giordano, V. (2012). América Latina. La construcción del orden. De la Colonia a la disolución de la dominación oligárquica. Tomo 1. Buenos Aires: Ariel.

Arata, N., y Southwell, M. (2014). Historia de la educación en América Latina: pasado, presente y porvenir. Un cues- 
tionario. En M. Sowthwell, y N. Arata (Ed.), Ideas en la educación latinoamericana. Un balance historiográfico. (pp. 201-202). Gonnet: UNIPE.

Arata, N. y Southwell, M. (2014). Itinerarios de la historiografía educativa en Latinoamérica a comienzos del siglo XXI. En M. Sowthwell, y N. Arata (Ed.), Ideas en la educación latinoamericana. Un balance historiográfico. (pp. 9-44). Gonnet: UNIPE.

Ardao, A. (1965). La idea de Latinoamérica. Marcha, XXVIII, 15-18. Ardao, A. (1978). La idea de la Magna Colombia. De Miranda a Hostos. Latinoamérica. Cuadernos de Cultura Americana. Núm. 2. México: Coordinación de Humanidades, Centro de Estudios Latinoamericanos, Facultad de Filosofía y Letras, Unión de Universidades de América Latina, Centro de Estudios Sobre La Universidad, UNAM.

Ardao, A. (1980). Génesis de la idea y el nombre de América Latina. Caracas: Centro de Estudios Latinoamericanos "Rómulo Gallegos"-V Consejo Nacional de la Cultura.

Bethell, L. (2012). Brasil y América Latina. Prismas. Revista de Historia Intelectual, (16), 53-78. Recuperado de http:// www.unq.edu.ar/catalogo/292-prismas-n-16-/-2012.php

Biagini, H. (2000). La Reforma Universitaria. Buenos Aires: Leviatán.

Bralich, J. (2014). ¿Qué es la "educación latinoamericana"? En M. Sowthwell, y N. Arata (Ed.), Ideas en la educación latinoamericana. Un balance historiográfico. (pp. 93-102). Gonnet: UNIPE.

Caicedo, T. (1857). Las dos Américas. El Correo de Ultramar. (16) Recuperado de http://www.filosofia.org/hem/185/ 18570215.htm

Carli, S. (2014). La historia de la educación en la Argentina en el escenario global: comunidades interpretativas, historia del presente y experiencia intelectual. En M. Sowthwell, y N. Arata (Ed.), Ideas en la educación latinoamericana. Un balance historiográfico. (pp. 103-120). Gonnet: UNIPE.

Carnoy, M. (1993). La educación como imperialismo cultural. México: Siglo XXI. 
Crossley, P. (2007). What is Global History? Cambridge: Cambridge Polity Press.

Chaunu, P. (1994). Historia de América Latina. Buenos Aires: Eudeba.

Devés, E. (2000). Del Ariel de Rodó a la CEPAL. Buenos Aires: Biblos, Centro de Investigaciones Diego Barros Arana.

Ford, A. (1994). Culturas populares y medios de comunicación. En A. Ford (Ed), Navegaciones. Comunicación, cultura y crisis. (pp. 71-76). Buenos Aires: Amorrortu.

Funes, P. (2007). América Latina: Los nombres del nuevo mundo. Argentina: Argentina. Ministerio de Educación, Ciencia y Tecnología. Recuperado de http://www.bnm.me.gov. ar/giga1/documentos/EL002323.pdf

Gallego, M., Eggers-Brass, T. y Gil, F. (2006). Historia latinaomericana 1700-2005. Buenos Aires: Maipue.

García, G. (1982). La soledad de América Latina. Discurso de aceptación del Premio Nobel. Recuperado de https://cvc. cervantes.es/actcult/garcia_marquez/audios/gm_nobel. htm.

Gómez, M. y Corenstein, M. (2013). Reconfiguración de lo educativo en América Latina. Experiencias pedagógicas alternativas. México: Universidad Nacional Autónoma de México.

Gonçalves, J., Sooma, y J.C. (2014). Visiones de América, Educación y Reformas Educativas: matices, acuerdos y diferencias. En M. Sowthwell, y N. Arata (Ed.), Ideas en la educación latinoamericana. Un balance historiográfico. (pp. 121-142). Gonnet: UNIPE.

Halperin, T. (2005). Historia Contemporánea de América Latina. Madrid: Alianza.

Haya, R. (1995). Significado político del nombre. A propósito de un prólogo de D. Luis Jiménez de Asúa. En R. Haya de la Torre (Ed.) Obras Escogidas 1, (1). (pp 1829). Perú: Comisión del Centenario del Nacimiento de Víctor Raúl Haya de la Torre. Recuperado de https://doi. org/10.2307/2908352

Herrera, M. y Cárdenas, Y. (2014). Infancia y subjetivación en América Latina. Apuntes para la historia de la educación y 
la cultura. En M. Sowthwell, y N. Arata (Ed.), Ideas en la educación latinoamericana. Un balance historiográfico (pp. 181-200). Gonnet: UNIPE. Recuperado dehttp://www. biblioteca.org.ar/libros/70738.pdf

Leslie, B. (1990). Historia de América Latina. 1. América Latina colonial: La América precolombina y la conquista. Barcelona: Crítica.

Mariátegui, J.C. (1928). Aniversario y balance. Amauta, (2) 17. Recuperado de https:/www.marxists.org/espanol/mariateg/1928/sep/aniv.htm

Martí, J. (2001). Carta a Manuel Mercado. 1895. Campamento dos Ríos. En J. Martí (Ed.) Obras completas. Cuba. Política y Revolución. (4) (pp. 167-170). La Habana: Centro de Estudios Martianos - Karisma Digital. Recuperado de http://www.josemarti.cu/utilidades/

Martinez, A. (2004). De la escuela expansiva a la escuela competitiva. Dos modos de modernización en América Latina. Bogotá: Anthropos.

Mignolo, W. (2005). La idea de América Latina. La herida colonial y la opción decolonial. Barcelona: Gedisa. Recuperado de https://doi.org/10.1017/CBO9781107415324.004

O’Gorman, E. (1958). La invención de América. México-Buenos Aires: Fondo de Cultura.

Phelan, J. (1968). Pan-Latinism, French intervention in México (1861-1867) and the genesis of the idea of Latin America. En Ortega y Medina, Juan Antonio. Conciencia y autenticidad históricas. Escritos en homenaje a Edmundo O'Gorman (pp. 279-298). México: UNAM.

Phelan, J. (1979). El origen de la idea de América. Latinoamérica. Cuadernos de Cultura Americana. Núm. 31. México: Coordinación de Humanidades, Centro de Estudios Latinoamericanos, Facultad de Filosofía y Letras, Unión de Universidades de América Latina, Centro de Estudios Sobre La Universidad, UNAM.

Piñeiro, C. (2006). Pensadores latinoamericanos del siglo XX. Ideas, Utopia y destino. Buenos Aires: Editora Iberoamericana. Siglo XXI. 
Portantiero, J.C. (1987). Estudiantes y politica en América Latina. Siglo Veintiuno España, Argentina, Colombia.

Prieto, L. (1980). El estado y la educación en América Latina. Caracas, Venezuela: IESALC-UNESCO.

Puiggrós, A. (1980). Imperialismo y Educación en América Latina. México: Nueva Imagen.

Puiggrós, A. (1990). Sujetos, disciplina y currículum en los orígenes del sistema educativo argentino. Historia de la educación argentina. Tomo 1. Buenos Aires: Galerna.

Puiggrós, A. (1996). Presencias y ausencias en la historiografía pedagógica latinoamericana. En H.R. Cucuzza (Ed.), Historia de la educación en debate (pp. 91-123). Buenos Aires: Miño y Dávila.

Puiggrós, A. (1998). La educación popular en América Latina. Origenes, polémicas y perspectivas. Buenos Aires: Miño y Dávila.

Puiggrós, A. y Mc. Lharen, P. (1993). An interview with Adriana Puiggrós of Argentina. The dilemas of latin American Educational Systems and the Work of Paulo Freire. Internacional Journal of Educational Reform, 2, 195-196.

Puiggrós, A. y Gagliano, R. (2004). La fábrica del conocimiento. Los saberes socialmente productivos en América Latina. Buenos Aires: Homo Sapiens-APPEAL.

Puiggrós, A. y Gómez, M. (1994). Alternativas pedagógicas. Sujetos y prospectiva de la Educación Latinoamericana. Buenos Aires: Miño y Dávila.

Puiggrós, A. y Lozano, C. (1995). Historia de la educación en Iberoamérica (1945-1992). Buenos Aires: Miño y Dávila.

Puiggrós, A. y Rodríguez, L. (2009). Saberes: reflexiones, experiencias y debates. Buenos Aires: Galerna.

Quijada, M. (1998). Sobre el origen y difusión del nombre "América Latina" (o una variación heterodoxa en torno al tema de la construcción social de la verdad). Revista de Indias, LVIII (214), 595-616. Recuperado de https://doi. org/10.3989/revindias.1998.i214.749

Quijano, A. (2007). Prólogo. En J.C. Mariátegui, Siete ensayos de la realidad peruana. Venezuela: Bibloteca Ayacucho. Recuperado de http://scholar.google.com/scholar?hl=en 
\&btnG=Search\&q=intitle:siete+ensayos+de+interpretaci on+de+la+realidad+peruana\#0

Rancière, J. (1988). Ecole, production, égalité. En L'école de la démocratie. Edilig, Foundation Diderot. Recuperado de http://www.horlieu-editions.com

Rancière, J. (2008). La lengua de la emancipación. Prólogo En J. Jacotot, Enseñanza universal. Lengua materna (pp. 1121). Buenos Aires: Cactus.

Ribeiro, D. (1969). Las Américas y la civilización. Buenos Aires: Colihue.

Ribeiro, D. (1979). A América Latina existe? Ensaios Insolitos, $217-$ 225. Recuperado de http://icaadocs.mfah.org/icaadocs/ ELARCHIVO/RegistroCompleto/tabid/99/doc/807738/ language/es-MX/Default.aspx

Rodó, J.E. (2003). Ariel. Buenos Aires: Biblioteca Virtual Universal. Recuperado de http://www.biblioteca.org.ar/libros/70738.pdf

Rodríguez, L. (2015). Paulo Freire, una biografía intelectual. Surgimiento y maduración de la Pedagogía del Oprimido. Buenos Aires: Colihue.

Rodríguez, L. (2018). América Latina como lugar de enunciación. Revista Fermentario. (1).(12), 169-184. Recuperado de http://www.fermentario.fhuce.edu.uy/index.php/fermentario/article/view/311/397\%0A

Rojas, M. (1986). Bilbao y el hallazgo de América latina: Unión continental, socialista y libertaria. Cahiers Du Monde Hispanique et Luso-Brésilien. (46), 35-47. Recuperado de http://www.persee.fr/doc/carav_0008-0152_1986_num _46_1_2261

Rojas, M. (1997). Los Cien Nombres de América. Eso que descubrió Colón. Costa Rica: Universidad de Costa Rica.

Roldán, M.E. (2002). El sistema de enseñanza mutua y la cultura cívica durante los primeros años de la república independiente de México. Historia Caribe. (7), 113-136.

Roldán, M.E. (2013). Para “ desnacionalizar ” la historia de la educación: reflexiones en torno a la difusión mundial de la escuela lancasteriana en el primer tercio del siglo XIX 
De-Nationalizing the History of Education: Reflections on the Global Diffusion of the Monitori, (1), 171-198.

Rostworowski, M. (2008). Historia del Tahuantinsuyu. Serie Historia andina. Lima: Instituto de Estudios Peruanos.

Sarmiento, D.F. (1953). Facundo. Buenos Aires: Estrada.

Tisserand, L.M. (1861). Situation de la latinité. Revue Des Races Latines: Française, Espagnole, Italienne, Portugaise, Belge, Autrichienne, Brésilienne et Hispano-Américaine: Religion, Histoire, Littérature, Sciences, Arts, Industrie, Finances, Commerce 24(56), 497-505.

Toro, P. (2014). Rasgos comunes y excepcionalidades: una tensión en la historia de la educación latinoamericana. Una mirada desde Chile. En M. Sowthwell, y N. Arata (Ed.), Ideas en la educación latinoamericana. Un balance historiográfico. (pp. 79-92). Gonnet: UNIPE.

Tünnermann, C. (1991). Historia de la Universidad en América Latina. Desde la época colonial a la Reforma de Córdoba. San José de Costa Rica: Editorial Universitaria Centroamericana.

UNLa. (2017). Los nombres de América Latina. En Atlas histórico de América Latina y el Caribe (pp. 637-657). Buenos Aires: Universidad Nacional de Lanús. Recuperado de http://atlaslatinoamericano.unla.edu.ar/presentacion.php Weinberg, G. (1984). Modelos educativos en la historia de América Latina. Buenos Aires: Kapelusz.

Weinberg, G. (1986). La educación como sistema de ideas en América Latina. En L. Zea (Ed.), América Latina en sus ideas (pp. 432-445). México: UNESCO-Siglo XXI.

Zea, L. (1977). Latinoamérica Tercer Mundo. México: Extemporáneo.

Zemelman, H. (1992a). Los horizontes de la razón. Uso crítico de la teoría. Barcelona: Anthropos.

Zemelman, H. (1992b). Los horizontes de la razón. Dialéctica y apropiación del presente. Barcelona: Antrophos.

Zemelman, H. (2011). Conocimiento y sujetos sociales. La Paz: OSFAM-Vicepresidencia del Estado. Presidencia de la Asamblea Legislativa Plurinacional Bolivia. 